\title{
Comparing climate change indices between a northern (arid) and a southern (humid) basin in Mexico during the last decades
}

\author{
Martín José Montero-Martínez, Julio Sergio Santana-Sepúlveda, Naydú Isabel Pérez-Ortiz, \\ Óscar Pita-Díaz, and Salvador Castillo-Liñan
}

Hydrometeorology, Mexican Institute of Water Technology, Jiutepec, Mor., 62550, Mexico

Correspondence: Martín José Montero-Martínez (martin_montero@tlaloc.imta.mx)

Received: 21 February 2018 - Revised: 20 June 2018 - Accepted: 13 August 2018 - Published: 31 August 2018

\begin{abstract}
It is a matter of current study to determine potential climate changes in different parts of the world, especially in regions like a basin which has the potential to affect socioeconomic and environmental issues in a defined area. This study provides a comparison between several climate change indices trends of two very different basins in Mexico, one located in the northern arid region (the Conchos River basin) and the other in the southern humid area (the Usumacinta River basin). First, quality control, homogenization, and completion of the missing data were applied before calculating the climate change indices and their respective trends for the combined period 1961-1994. A clear warming signal was found for the two basins in addition to an increment in the DTR, in agreement with other studies in Mexico. Also, the Conchos River basin was found to be more humid and the Usumacinta River basin drier, in accordance to a supposed seesaw behavior indicated in previous analysis.
\end{abstract}

\section{Introduction}

The Conchos River basin (hereinafter CRB) is located at the northern part of Mexico and covers an area around $72000 \mathrm{~km}^{2}$ and its range of altitudes goes from 1000 to almost $2500 \mathrm{~m}$, most of the region is enclosed within an arid area with a total annual precipitation ranging from 200 to $850 \mathrm{~mm}$. This basin is important because it is transboundary, and plays a crucial role in the Mexico-USA Water Treaty (signed in 1944) and also because of its relevance to the agricultural and livestock issues. In contrast, the Usumacinta River basin (hereinafter URB) covers around $31000 \mathrm{~km}^{2}$ (only in Mexico) and is confined to a tropical humid area with a total annual precipitation from 1300 to $3200 \mathrm{~mm}$, and terrain altitudes range from 0 to $2000 \mathrm{~m}$ (Fig. 1). The Usumacinta River is the largest one in Mexico and it represents a key part in the biodiversity and economy of one of the less developed regions in Mexico; furthermore it drains over the Lacandon region, the largest rainforest in the country.

The ETCCDI has been coordinating an international effort to develop, calculate, and analyze a suite of indices so that individuals, countries, and regions can calculate the indices in exactly the same way such that their analyses will fit adequately into the global picture (Karl et al., 1999; Peterson, 2005). The goal in this work is to calculate those indices over the two basins mentioned above and have a preliminary examination of the possible consequences of global warming in this part of the world.

Unfortunately for Mexico, like in many parts of the world, there is a lack of quantity and quality in the climate data, which translates in very few studies related to trends and evidence of climate change in the country (Redmond and Abatzoglou, 2014). Some of those studies have shown that the Diurnal Temperature Range (DTR) - which is itself one of the indices recommended by ETCCDI - is increasing in the recent past over Mexico, mainly because the maximum temperatures are warming at a higher rate than the minimum temperatures (Englehart and Douglas, 2005; Pavia et al., 2009). On the other hand, by using the Climatic Research Unit (CRU TS 3.1) data, Redmond and Abatzoglou (2014) found that the 1990s and the 2000s were the warmest decades on record for the region. In addition, Easterling et al. (2000) 


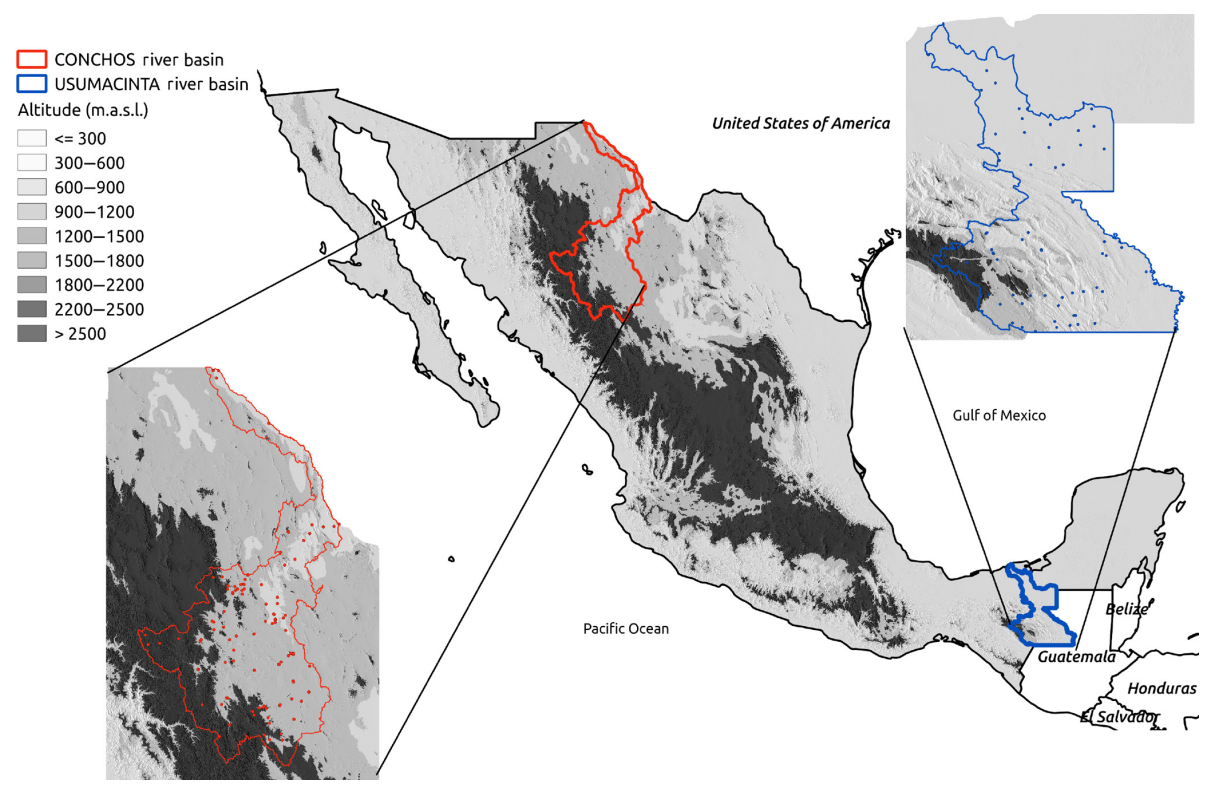

Figure 1. Location and altitudes (ma.s.1.) of the Conchos River basin (CRB) and the Usumacinta River basin (URB) in Mexico and their corresponding climate stations (110 for CRB and 67 for URB).

showed that all of North America (including Mexico) experienced a clear increase in heavy precipitation events in recent decades. Mateos et al. (2016) found, in general, an increase in maximum surface temperature and the diurnal temperature range (DTR) in 10 watersheds around Mexico. However, the paper concludes that the land-use and land-cover changes could be the main drivers of climate change in the region.

On a regional basis, Aguilar et al. (2005) provided the first analysis of the changes in temperature and precipitation extremes for Central America and Northern South America, with the URB included. Even though they conclude that the whole region is clearly warming, for the URB they found both positive and negative trends for warm days and nights and cold days and nights, although the warming signal prevailed. For several precipitation indices, they also found a mixture of both positive and negative trends for the same region. One interesting analysis that physically connects the two regions of study here is that of Mendez and Magaña (2009) who found that frequent droughts in northern Mexico coincide with anomalously humid conditions over southern Mexico and Central America, and vice versa. The scope of the present study provides a good opportunity to validate the above assumption even for the short period of time analyzed here.

\section{Data and methods}

The official climate data from CLICOM (CLImatological COMputing) historical database was used for Mexico. The CRB has a total of 110 climate stations while URB has 67 distributed as in Fig. 1. CLICOM database for Mexico usually only has a very basic quality control and it is necessary to apply a more robust procedure to assure good data quality.

Once climate data compilation was performed, a recommendation from ETCCDI (http://etccdi.pacificclimate.org/, last access: August 2018) was followed in the sense to carry on first the data quality control (QC) and the homogenization procedures before calculating the climate indices for the climate stations (Zhang and Yang, 2004). However, as a first step, it was decided to choose those 30 -year periods which have the greatest number of climate stations with at least the $80 \%$ of the data during that period. Those periods resulted to be 1961-1990 for the CRB (14 stations), and 1965-1994 for the URB (22 stations). After that, Climatol algorithm (Guijarro, 2013, 2018) was applied for the quality analysis, homogenization and completion of the missing data in the data series. Quality analysis is applied to minimize errors related to incorrect transcribed values in the data records. Homogenization means the removal of non-climatic changes which could be due to relocations or changes in the instrumentation. Climatol applies the Standard Normal Homogeneity Test (SNHT) to detect the breakpoints in the data series (inhomogeneities) (Alexandersson, 1986).

Once the homogenization and completion of the missing data were finished, the calculation of the climate change indices was performed with ClimPACT2 software (https: //github.com/ARCCSS-extremes/climpact2, last access: August 2018) for all the 36 stations found for both the CRB and the URB and the results are presented in the next section. 

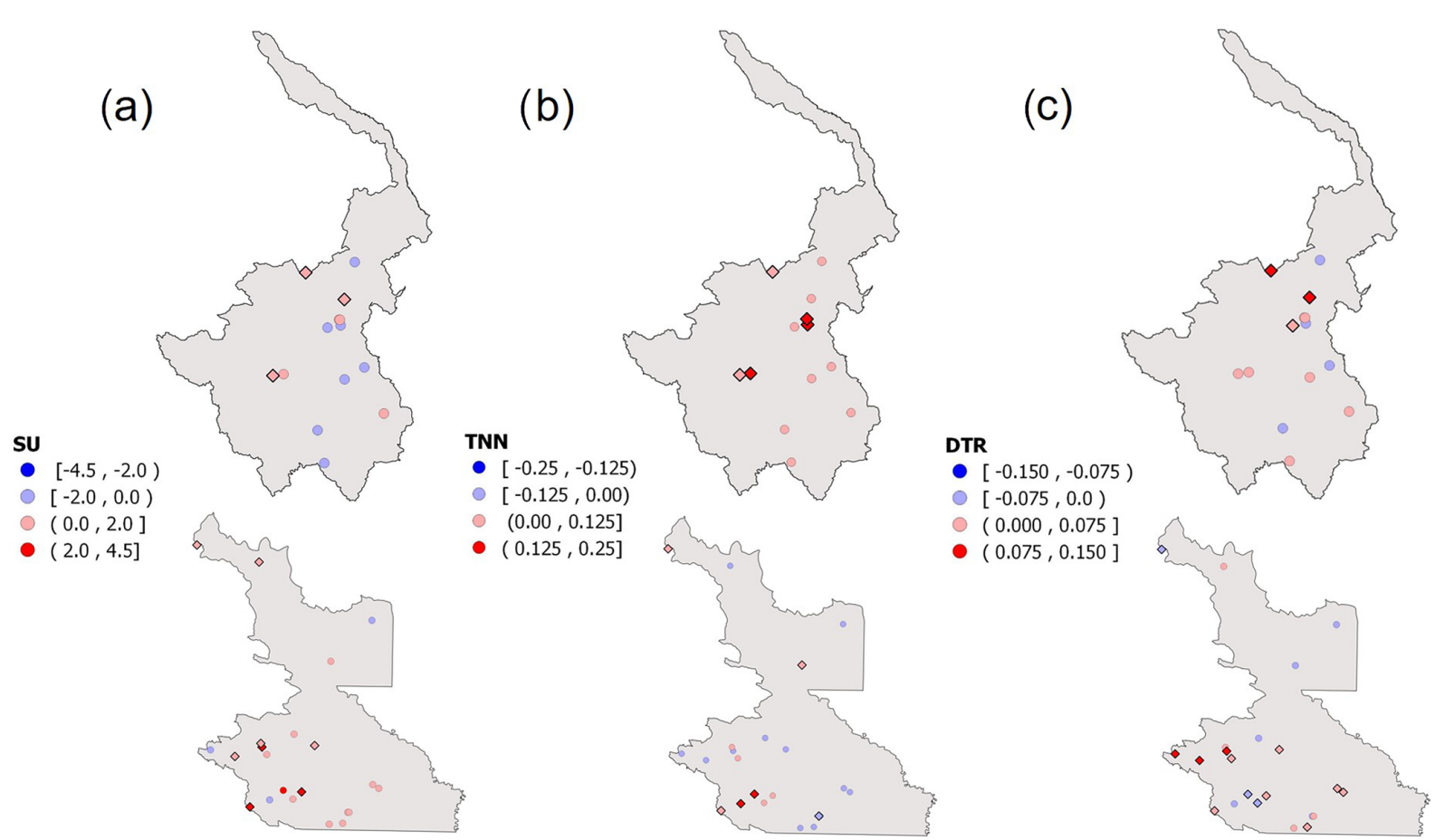

Figure 2. Trends for (a) SU (days $\mathrm{yr}^{-1}$ ), (b) $\mathrm{TNN}\left({ }^{\circ} \mathrm{Cyr}^{-1}\right.$ ), and (c) DTR $\left({ }^{\circ} \mathrm{Cyr}^{-1}\right.$ ) for the CRB (above) and URB (below) (indices explained in the text). Colors and symbols are explained in each index. Diamond symbols indicate the trends are statistically significant up to the $95 \%$ of confidence level.

\section{Results}

As mentioned above, the quality analysis and the homogenization processes were performed by using Climatol. Table 1 shows the breakpoints found in the selected climate stations from CRB (left) and URB (right) river basins.

Results of the linear trends for 10 (out of 27) climate change indices recommended by ETCCDI are presented on Table 2 (for the CRB) and Table 3 (for the URB). ClimPACT2 uses Ordinary Least Squares (OLS) regression to calculate the linear trends. The bold numbers are for those linear trends that resulted with statistical significance up to the $95 \%$ confidence level ( $p$-value $\leq 0.05$ ). In general, the trends with statistical significance were more common in the URB than in the CRB.

On the other hand, the geographical distributions of the linear trends of six of the ETCCDI indices are shown in Figs. 2 and 3 for the two basins. The linear trends for the summer days (SU, days when $T_{\max }>25^{\circ} \mathrm{C}$ ), the annual coldest daily minimum temperature (TNN), and the mean annual difference between daily maximum and minimum temperatures (DTR) are shown in Fig. 2.

The trends for SU show exactly $50 \%$ of positive and negative trend values for the $\mathrm{CRB}$, however, the three significant values are all positive. Also, the positive values of SU seem to dominate the western part of the basin and the negative ones the eastern part. On the other hand, positive trends of SU
Table 1. The number of breakpoints per station found here for every variable analyzed: precipitation (Prec), maximum and minimum temperature ( $T_{\max }$ and $T_{\min }$ respectively). Stations ID numbers (Sta-ID) are given for the CRB (left) and for the URB (right). The base period was 1961-1990 for the CRB and 1965-1994 for the URB.

\begin{tabular}{lrccrccc}
\hline Sta-ID & Prec & $T_{\max }$ & $T_{\min }$ & Sta-ID & Prec & $T_{\max }$ & $T_{\min }$ \\
\hline 8019 & & 1 & & 7104 & & 2 & 2 \\
8044 & 9 & 1 & 2 & 7121 & & 2 & 2 \\
8049 & 11 & & & 4024 & & & 1 \\
8050 & 3 & & & 7046 & 1 & & \\
8078 & & & 1 & 7047 & 2 & & \\
8085 & & 1 & 1 & 7051 & & 1 & \\
8092 & 2 & & & 7062 & 1 & 3 & \\
8157 & & & 2 & 7179 & & 1 & \\
8202 & 1 & & 1 & 7089 & 1 & 9 & 6 \\
10061 & 1 & 1 & & 27040 & & 2 & 2 \\
\hline
\end{tabular}

dominate almost all of the URB and up to 8 significant values were found for the region, all of them positive. Another interesting index to analyze is TNN in which all of the trends found for the CRB were positive even with up to 5 significant high values. For the URB, even though there is a mixture of positive and negative trends all around the basin much more significant values were positive (5 compared to only 1 negative). Also, positive trends dominate the southwestern part of the basin and negative trends the southeastern part. Finally, 
Table 2. Linear trends of 10 of the ETCCDI indices are given for 14 climate stations in the CRB (1961-1990). Stations ID numbers (StaID), geographical coordinates (Lat and Lon, in degrees) and altitudes (Alt, in m a.s.1.) are provided for every climate station. The ETCCDI indices are for the annual number of days when $T_{\max }>25$ degreeC $\left(\mathrm{SU}\right.$, days $\left.\mathrm{yr}^{-1}\right)$; annual warmest daily $T_{\max }\left(\mathrm{TXX}^{\circ}{ }^{\circ} \mathrm{C}\right.$ yr $\left.{ }^{-1}\right)$; annual coldest daily $T_{\min }\left(\mathrm{TNN},{ }^{\circ} \mathrm{C} \mathrm{yr}-1\right)$; mean annual difference between daily $T_{\max }$ and $T_{\min }$ (DTR, ${ }^{\circ} \mathrm{C} \mathrm{yr}{ }^{-1}$ ); annual percentage of days when $T_{\max }<10$ th percentile (TX10P, $\% \mathrm{yr}^{-1}$ ); annual percentage of days when $T_{\min }>90$ th percentile $\left(\mathrm{TN} 90 \mathrm{P}, \% \mathrm{yr}^{-1}\right.$ ); maximum annual number of consecutive dry days (Prec $<1 \mathrm{~mm})(\mathrm{CDD}$, in days); maximum annual number of consecutive wet days (Prec $\geq 1 \mathrm{~mm})(\mathrm{CWD}$, in days); annual total precipitation (PRCPTOT, mm); annual sum of daily Prec $>$ 99th percentile (R99P, mm). Bold typeface indicates statistically significant trends.

\begin{tabular}{lcccrrrrrrrrrr}
\hline Sta-ID & Lat & Lon & Alt & SU & TXX & TNN & DTR & TX10P & TN90P & CDD & CWD & PRCPTOT & R99P \\
\hline 8019 & 28.27 & -105.49 & 1150 & 0.41 & -0.048 & 0.066 & 0.041 & $\mathbf{- 0 . 2 7 8}$ & -0.194 & $\mathbf{- 2 . 0 6 2}$ & 0.011 & 3.332 & 1.116 \\
8025 & 27.69 & -105.17 & 1223 & -0.28 & 0.045 & 0.081 & -0.005 & 0.049 & -0.256 & -0.146 & $\mathbf{0 . 0 9 4}$ & -0.799 & -1.536 \\
8044 & 28.20 & -105.47 & 1173 & -0.46 & -0.059 & $\mathbf{0 . 2 1 3}$ & -0.012 & 0.056 & -0.346 & -0.633 & 0.01 & 3.284 & 0.641 \\
8049 & 28.98 & -105.31 & 1080 & -0.44 & 0.01 & 0.094 & -0.027 & 0.133 & -0.033 & -0.942 & -0.063 & 2.651 & -0.455 \\
8050 & 27.59 & -106.16 & 1700 & 0.59 & -0.012 & $\mathbf{0 . 1 4 3}$ & 0.031 & -0.004 & -0.213 & -0.937 & $\mathbf{0 . 2 1 1}$ & 0.396 & -1.698 \\
8057 & 27.57 & -106.29 & 1600 & $\mathbf{1 . 0 0}$ & -0.045 & $\mathbf{0 . 1}$ & 0.013 & -0.11 & -0.11 & -1.018 & $\mathbf{0 . 2 0 9}$ & -2.095 & -2.111 \\
8078 & 26.91 & -105.73 & 1770 & -0.75 & -0.086 & 0.056 & -0.028 & 0.102 & -0.21 & -0.414 & $\mathbf{0 . 1 7 3}$ & 1.453 & -1.509 \\
8081 & 27.13 & -104.92 & 1370 & 0.57 & 0.044 & 0.092 & 0.023 & -0.073 & -0.107 & -1.947 & 0.008 & 2.093 & 0.261 \\
8085 & 27.54 & -105.41 & 1323 & -0.66 & 0.039 & 0.026 & 0.005 & 0.087 & -0.087 & 0.139 & $\mathbf{0 . 1 1 7}$ & -1.11 & -0.685 \\
8092 & 28.52 & -105.43 & 1093 & $\mathbf{1 . 1 7}$ & $\mathbf{0 . 1 0 4}$ & 0.043 & $\mathbf{0 . 1 3 6}$ & -0.159 & $\mathbf{- 0 . 3 2 7}$ & $\mathbf{- 1 . 3 8 4}$ & 0.07 & 3.296 & 0.374 \\
8102 & 28.27 & -105.48 & 1155 & 0.04 & 0.044 & $\mathbf{0 . 1 3 8}$ & 0.055 & 0.009 & 0.016 & -0.51 & -0.034 & 2.396 & 0.701 \\
8157 & 28.84 & -105.91 & 1270 & $\mathbf{0 . 7 0}$ & $\mathbf{0 . 1 2 3}$ & $\mathbf{0 . 1 2 3}$ & $\mathbf{0 . 0 9 1}$ & $\mathbf{- 0 . 2 8 6}$ & -0.148 & -1.408 & -0.011 & -0.652 & -0.385 \\
8202 & 28.17 & -105.63 & 1242 & -0.18 & $\mathbf{0 . 1 3 3}$ & 0.094 & $\mathbf{0 . 0 6 6}$ & $\mathbf{0 . 2 3 2}$ & $\mathbf{- 0 . 4 1 1}$ & 0.15 & 0.004 & 0.668 & -0.476 \\
10061 & 26.51 & -105.64 & 1800 & -0.14 & 0.068 & 0.101 & 0.001 & $\mathbf{0 . 2 6 5}$ & 0.038 & 0.731 & 0.006 & 1.363 & -0.84 \\
\hline
\end{tabular}

it is clear that both basins are dominated by positive DTR trends. In addition, all of the three significant values are positive for the CRB and most of them (10 out of 13 significant values) are also positive for the URB.

For the linear trends related to precipitation climate change indices, Fig. 3 shows the maximum annual number of consecutive wet days (Prec $\geq 1 \mathrm{~mm}$ ) (CWD); the annual total precipitation (PRCPTOT); and the annual sum of daily Prec > 99th percentile (R99P). Positive CWD trends dominate through most of the south and central part of the basin and all of the significant trends are also positive. On the other hand, for the URB, both positive and negative trends are observed for CWD (the same for the significant trends); while negative trends dominate the eastern part of that region. As for the trends of R99P, it is shown that negative trends prevailed for both basins, even though only a few resulted to be statistically significant and all of them in the URB. Finally, for PRCPTOT positive trends dominate the CRB (10 out of 14 stations) and negative trends prevail in the URB (17 out of 22 stations), including two significant high positive trends for the two northernmost stations of the basin.

\section{Conclusions}

It is notable that just $13 \%$ for the CRB and $33 \%$ of the climate stations for the URB satisfied WMO requirements of having at least $80 \%$ of the data in a full 30 -year climate period. Certainly, this example reflects the importance to adequately maintain climate stations if we want to increase our confidence in calculating long-term climate change indices and trends. Unfortunately, not enough data was available to analyze confidently the most recent decades (the 1990s and 2000s) which are certainly the warmest according to global mean records (IPCC, 2014).

However, even with those constraints, the analysis shown here is valuable in the sense that it provides a valuable set of high-quality climate stations during the combined period of 1961-1994. Thus, with respect to the surface temperature climate change indices analyzed here, it is concluded that:

- The increase in SU, especially for the URB, is in agreement with a warming signal and that is corroborated by the relatively high number of significant positive trends there. For the CRB, all of the three significant values were positive supporting also a warming signal.

- The analysis for TNN, also supports a warming signal in the sense that all of the stations showed a positive trend for this index in the CRB and, even though for the URB there was a mixture of positive and negative signals, the significant values were most of them positive.

- In addition, it was found that most of the DTR trends increase for both basins, meaning a rise in the surface temperature climate extremes. This result is in agreement with those found by other authors in Mexico (Englehart and Douglas, 2005; Pavia et al., 2009; Mateos et al., 2016) such as it was discussed earlier.

From the analysis of the indices related to precipitation, it is concluded that:

- The analysis shown for the DTR and PRCPTOT trends seem to support the idea that the CRB was getting more 
Table 3. As Table 2 but for the URB (1965-1994).

\begin{tabular}{|c|c|c|c|c|c|c|c|c|c|c|c|c|c|}
\hline Sta-ID & Lat & Lon & Alt & SU & $\mathrm{TXX}$ & TNN & DTR & TX10P & TN90P & CDD & CWD & PRCPTOT & R99P \\
\hline 4024 & 18.25 & -92.09 & 4 & 0.533 & 0.039 & -0.008 & 0.001 & -0.076 & 0.559 & 0.213 & -0.085 & -26.594 & -0.333 \\
\hline 7006 & 16.74 & -92.04 & 1240 & 2.521 & 0.012 & -0.03 & 0.085 & -0.255 & -0.321 & -0.152 & -0.016 & 5.865 & -0.719 \\
\hline 7031 & 16.66 & -92.26 & 2100 & 0.672 & 0.031 & -0.023 & 0.11 & -0.319 & -0.164 & 0.345 & -0.576 & -3.488 & -0.187 \\
\hline 7043 & 16.42 & -91.08 & 510 & 0.241 & 0.018 & -0.012 & 0.032 & -0.042 & -0.333 & -0.109 & -0.106 & -6.019 & -0.864 \\
\hline 7046 & 16.22 & -91.33 & 379 & 0.045 & -0.023 & -0.088 & -0.012 & 0.032 & -0.208 & -0.067 & -0.272 & 7.517 & 4.404 \\
\hline 7047 & 16.13 & -91.37 & 360 & 0.409 & 0.016 & -0.031 & $\mathbf{0 . 0 3}$ & -0.096 & -0.218 & -0.029 & -0.254 & 2.831 & 8.69 \\
\hline 7051 & 16.85 & -91.78 & 740 & 0.278 & 0.008 & 0 & -0.014 & -0.014 & 0.132 & 0.014 & 0.049 & -4.394 & -1.342 \\
\hline 7055 & 16.38 & -91.71 & 1596 & 2.346 & -0.051 & 0.06 & 0.056 & -0.31 & -0.072 & 0.005 & -0.147 & -0.077 & 3.136 \\
\hline 7062 & 16.39 & -91.86 & 1469 & 2.079 & -0.187 & 0.142 & -0.056 & -0.634 & 0.352 & -0.36 & 0.11 & -0.674 & -3.134 \\
\hline 7076 & 16.71 & -92.46 & 1990 & -0.44 & -0.016 & -0.007 & 0.087 & -0.47 & -0.251 & -0.004 & -0.004 & -0.195 & -0.401 \\
\hline 7089 & 16.22 & -91.32 & 327 & 0.381 & 0.032 & -0.06 & 0.009 & 0.033 & 0.002 & 0.086 & -0.272 & 7.462 & 12.222 \\
\hline 7096 & 16.32 & -91.78 & 1120 & 0.051 & -0.045 & 0.066 & -0.025 & -0.136 & 0.121 & -0.216 & 0.481 & 12.513 & -1.221 \\
\hline 7104 & 16.31 & -91.97 & 1512 & -0.006 & -0.071 & 0.185 & -0.013 & -0.531 & -0.293 & -0.845 & 0.122 & -1.601 & 0.918 \\
\hline 7107 & 16.76 & -91.61 & 600 & 0.648 & 0.001 & -0.001 & 0.037 & -0.174 & -0.261 & -0.09 & 0.453 & -4.114 & -3.054 \\
\hline 7108 & 16.77 & -92.05 & 1200 & 0.825 & -0.007 & 0.004 & 0.008 & -0.099 & 0.104 & -0.028 & 0.024 & -2.748 & -3.058 \\
\hline 7121 & 16.45 & -91.13 & 1000 & 0.128 & 0.086 & -0.081 & 0.024 & 0.094 & -0.012 & 0.099 & -0.003 & -3.232 & -4.829 \\
\hline 7154 & 16.12 & -91.48 & 720 & 0.594 & 0.032 & -0.049 & 0.011 & -0.135 & 0.297 & 0.585 & -0.335 & -7.36 & 4.935 \\
\hline 7179 & 16.68 & -92 & 1250 & 1.108 & 0.049 & 0.012 & 0.047 & -0.171 & -0.138 & -0.27 & 0.082 & -0.758 & -3.01 \\
\hline 7205 & 16.25 & -92.13 & 1630 & 4.453 & 0.101 & 0.087 & 0.043 & -0.403 & 0.186 & -0.248 & -0.007 & -2.108 & -1.753 \\
\hline 27004 & 17.45 & -91.49 & 14 & 0.326 & -0.028 & 0.062 & -0.022 & -0.05 & 0.328 & -0.107 & -0.051 & -6.657 & -4.52 \\
\hline 27040 & 17.79 & -91.16 & 44 & -0.071 & 0.022 & -0.072 & -0.011 & 0.172 & 0.436 & 0.012 & -0.083 & -2.606 & 2.191 \\
\hline 27050 & 18.38 & -92.6 & 2 & 0.502 & -0.007 & 0.119 & -0.033 & -0.19 & 0.511 & -0.233 & 0.023 & -19.006 & -1.551 \\
\hline
\end{tabular}
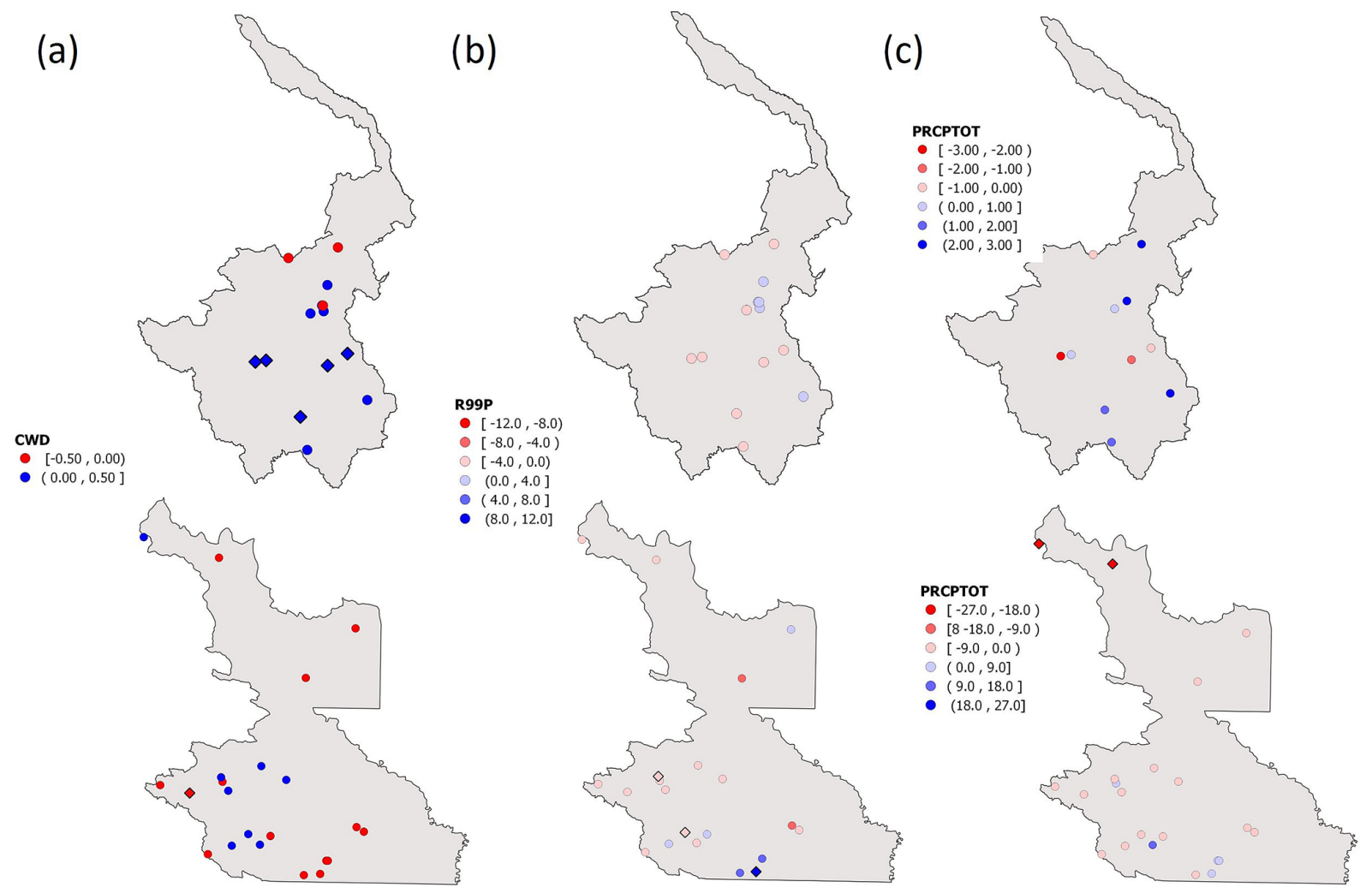

Figure 3. Same as in Fig. 2 but for (a) CWD (days $\left.\mathrm{r}^{-1}\right)$, (b) R99P $\left(\mathrm{mm} \mathrm{yr}^{-1}\right.$ ), and (c) PRCPTOT ( $\mathrm{mm} \mathrm{yr}^{-1}$ ) for the CRB (above) and the URB (below). Note the change in scale for PRCPTOT. 
humid during 1961-1990 period. On the other hand, the same analysis for the URB (1965-1994) seems to show a region getting drier. Even though the periods of analysis are not exactly the same, there is a 25 -year similar period (1965-1990) in which the results could be comparable somehow. In that sense, the above result seems to be in agreement with Mendez and Magaña (2009) given that they found a kind of dipole that when the northern part of Mexico is drier the southern part is more humid.

- By combining the surface temperature and precipitation trend analysis for the URB, it was shown a mixture of positive and negative trends for the whole region such as it was found previously by Aguilar et al. (2005) as discussed earlier. A possible explanation of those results is that the URB is a complex topographical area in which different local microclimates could prevail in relatively closed zones because of the altitude differences. Another possibility is that the regional climate signal differences could be directly related to land-use and land-cover changes given that this region is the one with more diversity in the whole country.

More future analyses are necessary to study the similarities and differences between these two contrasting areas. For that, it would be necessary to extend not only more climate indices (such as SPI, SPEI, etc.) but also to extend the period of analysis to be more certain on the conclusions found here.

Data availability. As mentioned above, the climate data compiled for this study was obtained directly from CLICOM. The whole CLICOM database for Mexico can be accessed online at: http: //clicom-mex.cicese.mx/mapa.html (last access: August 2018). In addition, the original databases and generated products of this paper are available online: http://gradiente.imta.mx/productos (last access: August 2018).

Supplement. The supplement related to this article is available online at: https://doi.org/10.5194/asr-15-231-2018-supplement.

Author contributions. MJMM led the research, made calculations and wrote the paper. JSSS provided key programs for the paper. OPD generated the figures. NIPO and SCL made calculations for the Usumacinta and Conchos respectively.

Competing interests. The authors declare that they have no conflict of interest.

Special issue statement. This article is part of the special issue "17th EMS Annual Meeting: European Conference for Applied Meteorology and Climatology 2017”. It is a result of the EMS Annual
Meeting: European Conference for Applied Meteorology and Climatology 2017, Dublin, Ireland, 4-8 September 2017.

Acknowledgements. Thanks to the financing granted by the Sectorial Fund for Environmental Research SEMARNAT-CONACYT, Call S0010-2014-1, through project 249435. Also, we are very grateful to M. S. Jorge Luis Vázquez on getting the data and to Israel Torres on some informatics issues.

Edited by: Ole Einar Tveito

Reviewed by: two anonymous referees

\section{References}

Aguilar, E., Peterson, T. C., Ramírez Obando, P., Frutos, R., Retana, J. A., Solera, M., Soley, J., González García, I., Araujo, R. M., Rosa Santos, A., Valle, V. E., Brunet, M., Aguilar, L., Álvarez, L., Bautista, M., Casta 'nón, C., Herrera, L., Ruano, E., Sinay, J. J., Sánchez, E., Hernández Oviedo, G. I., Obed, F., Salgado, J. E., Vázquez, J. L., Baca, M., Gutiérrez, M., Centella, C., Espinoza, J., Martínez, D., Olmedo, B., Ojeda Espinoza, C. E., Núñez, R., Haylock, M., Benavides, H., and Mayorga, R.: Changes in precipitation and temperature extremes in Central America and northern South America, 1961-2003, J. Geophys. Res.-Atmos., 110, D23107, https://doi.org/10.1029/2005JD006119, 2005.

Alexandersson, H.: A homogeneity test applied to precipitation data, Int. J. Climatol., 6, 661-675, https://doi.org/10.1002/joc.3370060607, 1986.

Easterling, D. R., Evans, J. L., Groisman, P. Y., Karl, T. R., Kunkel, K. E., and Ambenje, P.: Observed variability and trends in extreme climate events: a brief review, $\mathrm{B}$. Am. Meteorol. Soc., 81, 417-425, https://doi.org/10.1175/15200477(2000)081<0417:OVATIE>2.3.CO;2, 2000.

Englehart, P. J. and Douglas, A. V.: Changing behavior in the diurnal range of surface air temperatures over Mexico, Geophys. Res. Lett., 32, L01701, https://doi.org/10.1029/2004GL021139, 2005.

Guijarro, J. A.: User's guide Climatol. Balearic Islands Office, Spain: State Meteorological Agency (AEMET), available at: http://www.climatol.eu/ (last access: August 2018), 2013.

Guijarro, J. A.: Homogenization of climatic series with Climatol, Versión 3.1.1, Agencia Estatal de Meteorología (AEMET), D. T. en Islas Baleares, España, available at: http://www.climatol. eu/homog_climatol-en.pdf, last access: August 2018.

IPCC: Climate Change 2014: Synthesis Report, in: Contribution of Working Groups I, II and III to the Fifth Assessment Report of the Intergovernmental Panel on Climate Change, edited by: Core Writing Team, Pachauri, R. K., and Meyer, L. A., IPCC, Geneva, Switzerland, 151 pp., http://epic.awi.de/37530/1/IPCC_ AR5_SYR_Final.pdf (last access: August 2018), 2014.

Karl, T. R., Nicholls, N., and Ghazi, A.: CLIVAR/GCOS/WMO workshop on indices and indicators for climate extremes: Workshop summary, Climatic Change, 42, 3-7, https://doi.org/10.1023/A:1005491526870, 1999.

Mateos, E., Santana, J. S., Montero-Martínez, M. J., Deeb, A., and Grunwaldt, A.: Possible climate change evidence in ten 
Mexican watersheds, Phys. Chem. Earth Pt. A/B/C, 91, 10-19, https://doi.org/10.1016/j.pce.2015.08.009, 2016.

Méndez, M., and Magaña, V.: Regional aspects of prolonged meteorological droughts over Mexico and Central America, J. Climate, 23, 1175-1188, https://doi.org/10.1175/2009JCLI3080.1, 2010.

Pavia, E. G., Graef, F., and Reyes, J.: Annual and seasonal surface air temperature trends in Mexico, Int. J. Climatol., 29, 13241329, https://doi.org/10.1002/joc.1787, 2009.
Peterson, T. C.: Climate Change Indices, WMO Bulletin, 54, 83-86, 2005.

Redmond, K. T. and Abatzoglou, J. T.: Current climate and recent trends, in: Climate Change in North America, Springer, Cham, 53-94, 2014.

Zhang, X. and Yang, F.: RClimDex (1.0) User Guide, Climate Research Branch Environment Canada, Downsview, Ontario, Canada, http://etccdi.pacificclimate.org/RClimDex/ RClimDexUserManual.doc (last access: August 2018), 2004. 